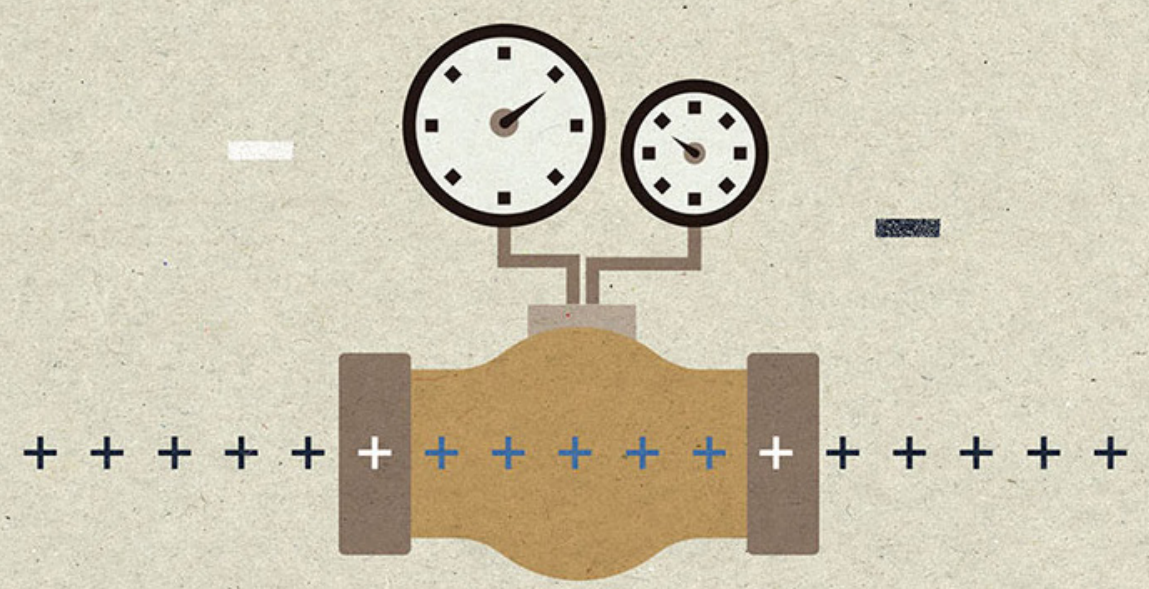

5agnes

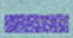




\title{
Avaliação da aderência do modelo regulatório brasileiro no segmento de exploração e produção da Indústria de óleo e gás às "boas práticas" apontadas na literatura econômica ${ }^{1}$
}

\author{
Brazilian Oil and Gas Exploitation \\ Regulatory Model: an evaluation of best \\ practices in the economic literature
}

Rodrigo Mendes Gandra* | Helder Queiroz Pinto Junior**

\section{Resumo}

O presente trabalho visa verificar o grau de aderência do modelo regulatório brasileiro no segmento de Exploração e Produção (E\&P) da indústria de Óleo e Gás às boas práticas apontadas na literatura econômica de regulação. Foi construído um sistema de pontuação para avaliar o modelo regulatório brasileiro em dois períodos de tempo: após a ratificação da Lei do Petróleo em 1997 que criou ANP e os contratos de concessão; e após as reformas ocorridas entre 2009 e 2010 com a criação dos contratos de partilha da produção, criação da PPSA e mudanças de atribuições da ANP e do CNPE. Pretende-se identificar também se, entre estes dois períodos, houve um aumento ou queda de aderência regulatória. Considerando os critérios adotados neste trabalho, pode-se assumir que o modelo regulatório brasileiro de E\&P é aderente às boas práticas apontadas na literatura econômica.

Palavras-chave: Regulação, Exploração e Produção, Indústria de Óleo e Gás.

\begin{abstract}
The present work aims to verify the degree of adherence of Brazilian E\&P regulatory model of the Oil and Gas industry to the good practices pointed out in the economic regulation literature. It was constructed a scoring system to help the evaluation of the Brazilian regulatory model in two time periods: after the ratification of the Petroleum Law in 1997 that created ANP and the concession contracts; and after the reforms occurred between 2009 and 2010 with the creation of sharing production contracts, creation of PPSA, change of ANP's and CNPE's attributions. The importance of the work is to identify whether, between these two periods, there was an increase or fall of regulatory adherence. Considering the criteria adopted in this paper, one can assume that the Brazilian E\&P regulatory model adheres to good practices pointed out in the economic literature.
\end{abstract}

Keywords: Regulation, Exploration and Production, Oil and Gas Industry.

\footnotetext{
* Doutor em Ciências, Políticas Públicas, Estratégias e Desenvolvimento (PPED) da Universidade Federal do Rio de Janeiro. https://orcid.org/0000-0002-4269-2805. E-mail: rodgandra@gmail.com

** Professor do Instituto de Economia da Universidade Federal do Rio de Janeiro. https://orcid.org/0000-0002-8996-3027.E-mail: helder@ie.ufrj.br
} 


\section{INTRODUÇÂO}

O presente trabalho visa verificar o grau de aderência do modelo regulatório brasileiro no segmento de Exploração e Produção (E\&P), upstream, da indústria de Óleo e Gás às boas práticas apontadas na literatura econômica sobre regulação. Foi construído um sistema de pontuação para avaliar o modelo regulatório brasileiro em dois períodos de tempo: após a ratificação da Lei do Petróleo em 1997 que criou ANP e os contratos de concessão; e após as reformas ocorridas entre 2009 e 2010 com a criação dos contratos de partilha da produção, criação da PPSA e mudanças de atribuições da ANP e do CNPE. Pretende-se identificar também se, entre estes dois períodos, houve um aumento ou queda de "aderência regulatória" que possa afetar os objetivos do Governo e as decisóes de investimento das empresas.

Apresar das diversas formas que os governantes podem utilizar para regular determinadas atividades econômicas setoriais e industrias, observa-se uma tendência mundial no uso de agências regulatórias independentes para zelar pelos interesses públicos. No Brasil não foi diferente e, no segmento de E\&P, esta implementação já acumula 20 anos de experiência. Inspirado nos trabalhos de Berg (2001), Baldwin, Cave e Lodge (2012) e Joskow (2005), foram listadas as principais atribuiçôes e características que um sistema regulatório (bem como as agências reguladoras) podem ter para aderir às "boas práticas de regulação”. Em seguida, para mapear o modelo de regulação no setor de E\&P brasileiro foi utilizado o trabalho de Caselli (2012) e Dias (2013). Por fim, foi apresentado o resultado do sistema de pontuação do "grau de aderência” com as justificativas.

\section{A IMPORTÂNCIA DA REGULAÇÃO NAS DECISÕES PRIVADAS DE INVESTIMENTO}

Devido à complexidade do mundo e falta de capacidade computacional das pessoas em geral, numa visão instrumental, North (1990, p. 27) considera que as instituiçóes servem para atenuar os problemas derivados da incerteza: restringindo as escolhas, reduzindo os custos de transação e facilitando a coordenação econômica e social. Para ele, a partir dos estímulos oferecidos pela matriz institucional, as diversas organizaçóes buscarão satisfazer seus objetivos. Raud-Mattedi (2005, p. 137) mostra que em Max Weber, o Estado, através a burocracia, também participa diretamente e indiretamente da difusão de uma mentalidade (ethos) capitalista, enfatizando a impessoalidade e racionalidade econômica. Isto é, a burocracia estatal acaba reforçando ou limitando a legitimidade do mercado. Émile Durkheim (1983: 63-66. Apud Raud-Mattedi, 2005, p. 138) corroborou com esta tese mos- 
trando que o próprio crescimento do individualismo não implica a diminuição do papel do Estado; pelo contrário, é justamente o Estado que legitima e garante o individualismo, induzindo o respeito aos direitos individuais. Ou seja, o Estado atua como um "órgão por excelência da disciplina moral”, pois influencia o mercado assegurando o respeito aos contratos, à propriedade privada e à justiça nas relaçóes de troca.

Berg (2001, p. 1) afirma que os investidores não comprometem o capital se houver instabilidade política e oportunismo, pois tornam esses investimentos excessivamente arriscados em relação aos retornos esperados e ao custo do capital. Segundo eles, o sistema de governança regulatória é determinante na credibilidade dos investidores, afetando a percepção de risco dos empresários na projeção dos fluxos de caixa esperados. Contudo Berg (2001, p. 6) ressalta que a governança regulatória de um país depende de suas instituiçóes formais (tais como o sistema jurídico e o direito de propriedade) e informais (tal como a cultura). Newbery (1999, p. 29) vai na mesma direção quando afirma: "what would be needed to persuade investors to sink their money into an asset that cannot be moved and will not pay itself for many years? Investors would have to be confident that they had secure title to the returns and that the returns would be sufficiently attractive. Durable investments thus require the rule of law, and specifically the law of property, which is a public good provided by the state".

Joskow (2005, p. 74) defende que o papel das agências regulatórias é de zelar para que os preços sejam "justos, razoáveis e não excessivamente discriminatórios”, garantindo que os consumidores não sejam cobrados mais do que o necessário para dar às empresas regulamentadas uma oportunidade razoável de recuperar custos incorridos de forma eficiente, incluindo uma taxa de retorno justa sobre seus investimentos. Sendo assim, os princípios que governam a regulação desempenham um importante papel na atração dos investimentos para os setores. Segundo Ferraz (2017, p. 10), em um mercado aberto à concorrência, cabe ao Governo elaborar e implementar um desenho de mercado bem estruturado, com a criação de instituições apropriadas e regras de funcionamento claras, assim como mecanismos de combate ao não-cumprimento dessas regras capazes de gerir conflitos existentes. Dessa forma, o Governo deve desencorajar comportamentos oportunistas dos atores, incluindo o seu próprio comportamento, de modo a transmitir segurança aos investidores privados. Baldwin, Cave e Lodge (2012, p. 415-416) ainda destacam que a necessidade de atrair investimentos privados nos países em desenvolvimento assume uma prioridade ainda maior quando estes países sofrem de limitação de recursos para realizar projetos de desenvolvimento econômico. Sendo assim, o desenho institucional e o 
modelo regulatório, que pode variar bastante, dos países afetam as decisões de investimentos e os objetivos dos governantes. De uma forma geral, a regulação idealmente visa ajustar os interesses privados aos interesses públicos. Gandra (2018) apresenta as justificativas regulatórias no segmento de E\&P Brasil entre 1997 e 2017.

\section{ESTRATÉGIAS REGULATÓRIAS E BOAS PRÁTICAS DE REGULAÇÃO}

Segundo Berg (2001, p. 16), as características de um sistema regulatório têm um impacto significativo no desempenho setorial. Assim como ele, Joskow (2005, p. 61-63) identifica uma variedade de arranjos organizacionais através dos quais preços, entrada e outros termos e condiçóes de serviço podem ser regulados. Eles apontam que o método favorito de regulamentação econômica nos EUA nos níveis estadual e federal são em formato de Independente Regulatory Commission (IRC) que, possuindo efetivo próprio de profissionais de diversas áreas, tem o dever de zelar pelos interesses públicos. Ambos concordam que, embora muitos fatores estejam além do controle de comissões regulatórias, tanto o design da agência, quanto os processos por ela utilizados são avaliados pela comunidade internacional de investimentos. Segundo Joskow (2005, p. 72), fica claro para estudiosos e formuladores de políticas que uma regulação efetiva pelo Governo exige conhecimentos especializados em áreas como engenharia, contabilidade, finanças e economia. Os reguladores também precisam de informaçóes sobre os custos, demanda, investimentos, sistema de gestão, financiamentos, produtividade, confiabilidade e atributos de segurança das empresas reguladas para desempenhar seus trabalhos. Outro ponto importante é a utilização dos processos concorrenciais de licitação (competitive biddings) para a escolha das empresas vencedoras na exploração de determinada atividade econômica. Joskow (2005, p. 64-65) argumenta que Demsetz (1968) era um entusiasta deste processo de licitação competitiva, pois poderia selecionar ex ante o candidato mais eficiente em termos de preço, embora no ex post existisse apenas uma única empresa no mercado.

No caso do upstream, Tolmasquin e Pinto Jr. (2011) classificam os diferentes marcos regulatórios do petróleo em função da propriedade do produto após a exploração do mesmo. A questão central para escolha do modelo pelos Governos é definir se a titularidade da produção de petróleo continua sob o controle do Estado ou se passa para a propriedade das concessionárias. Assim, segundo Dias (2013, p. 82), a classificação disposta na Figura 1 divide os regimes de exploração em dois grandes blocos: modalidades que garantem 
a propriedade exclusivamente estatal ao longo do processo de exploração do petróleo, "monopólio estatal", e modalidades que admitem a propriedade privada de "não exclusividade estatal”.

Figura 1: Classificação dos Marcos Regulatórios do Petróleo

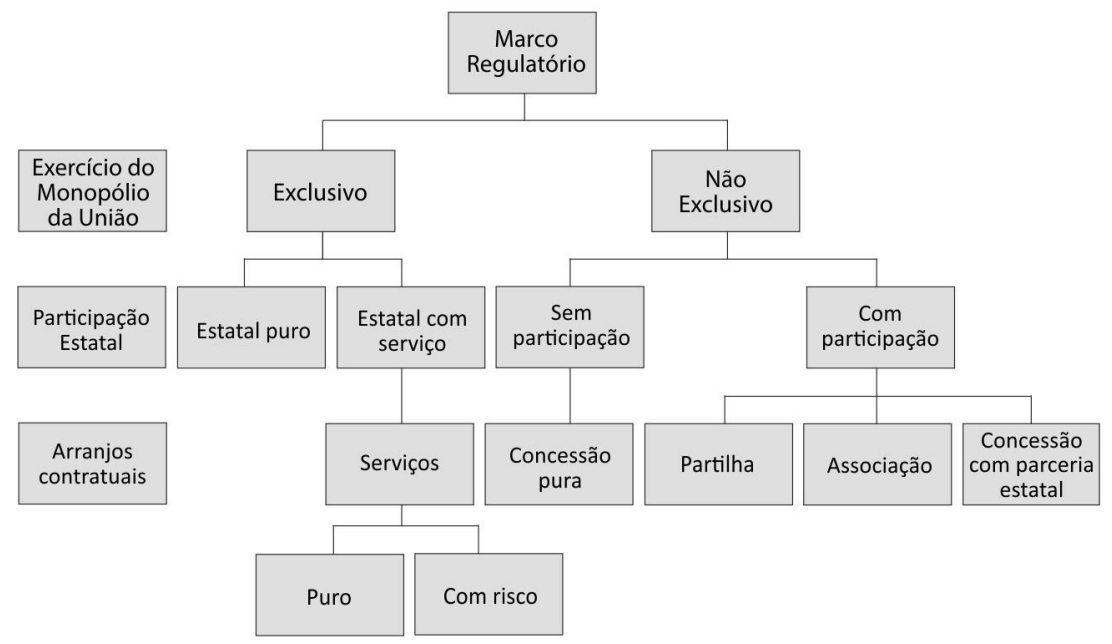

Fonte: Tolmasquin e Pinto Jr. (2011. Apud DIAS, 2013, p. 82)

Para avaliar se um sistema regulatório é satisfatório, faz-se necessário recorrer à algumas referências. Para Baldwin, Cave e Lodge (2012, p. 25), a tentação de alguns economistas é afirmar que uma regulamentação é boa se for eficiente no sentido da maximização da riqueza. Contudo, deve-se levar em consideração que a maximização da riqueza não fornece bases éticas para a ação, sendo assim, não pode justificar qualquer distribuição particular de direitos dentro da sociedade. A ideia de defesa dos interesses públicos deve estar presente. Assim, Baldwin, Cave e Lodge (2012, p. 27-39) destacam cinco critérios para avaliar uma boa regulação: A ação ou regime é apoiado pela autoridade legislativa? Existe um esquema adequado de prestação de contas? Os procedimentos são justos, acessíveis e abertos? O regulador está atuando com conhecimentos suficientes? As açóes ou o regime são eficientes?

Para avaliar se o sistema regulatório do upstream brasileiro está aderente às boas práticas listadas na literatura, este trabalho recorreu: aos cinco benchmarkings para avaliação da regulação de Baldwin, Cave e Lodge (2012); aos trabalhos de Joskow (2005) e Cintra (2013); e à pesquisa de comparativa 
de Berg (2001, p. 3-5) que, incluiu na sua lista de "Best Practice Regulation" os itens levantados do Australian Competition $\sigma^{\circ}$ Consumer Commission (1999). Além da configuração do modelo, Berg (2001, p. 5) ainda apresenta algumas atribuiçóes desejáveis desempenhadas pelas agências reguladoras no setor de energia elétrica dos EUA. Sem pretender ser exaustivo, com base nesta literatura, foram propostos 15 atributos para avaliação conforme abaixo.

i. Simplicidade do Sistema: o sistema regulatório não deve ser demasiadamente complexo dificultando a distinção das atribuiçôes, dos papeis e das responsabilidades dos agentes envolvidos.

ii. Eficácia do Sistema (Benefício $\times$ Custo): a relação entre o custo e o benefício deve ser avaliada quando da implementação de políticas e procedimentos regulatórios. Deve-se garantir que as regras ampliáveis fazem sentido do ponto de vista do desenvolvimento setorial, da defesa da concorrência e da defesa dos interesses públicos sem gerar burocracias complexas e sem ser extremante oneroso à sociedade.

iii. Previsibilidade e Consistência do Sistema: decisões dos policy makers devem ser previsíveis para facilitar o planejamento e as decisóes dos agentes de mercado e reduzir os riscos percebidos pelos investidores. Cintra (2013) observa que a clareza na interpretação e a estabilidade das regras do negócio estão diretamente ligadas ao chamado risco regulatório. Gandra (2014) destaca que, “(...) as regras do jogo devem ser bem definidas, claras e estáveis no longo prazo, para que os investidores se sintam atraídos e seguros a colocar seu capital no país. Nenhum investidor gosta de mudanças constantes nas regras tributárias, nas regras regulatórias, principalmente porque os montantes investidos estão na casa dos milhôes e bilhôes de dólares".

\section{iv. Coordenação entre Regulação Setorial Específica e demais Obje-} tivos da Sociedade: deve haver alguma coordenação entre o órgão regulador do setor com os demais órgãos e agências governamentais. Como exemplo, o órgão regulador de E\&P deve ter alinhamento prévio com os órgãos ambientais, tais como o Instituto Brasileiro do Meio Ambiente e dos Recursos Naturais Renováveis (IBAMA) e o Instituto Estadual do Ambiente (INEA), no que diz respeito ao oferecimento de áreas para licitação.

v. Existência de Agência Regulatória: a presença de uma agência se tornou uma boa prática nos países em que o Estado deixou de ser provedor de determinados serviços e passou para o mercado. 
vi. Responsabilidade da Agência na Implementação da Política Setorial: agência tem responsabilidade pela implementação das diretrizes regulatórias no setor.

vii. Flexibilidade da Agência: a agência deve adequar suas respostas às mudanças de condiçốes institucionais, ambientais e tecnológicas.

viii. Autonomia na Tomada de Decisões da Agência: o regulador deve ter certo grau de independência nas decisóes técnicas que impactam o setor a fim de promover a confiança pública. Segundo Joskow (2005, p. 75), a agência e seus funcionários devem ter suas decisões apoiadas em processos e procedimentos administrativos internos, sofrendo pouca influencias das instâncias legislativas e executivas.

ix. Independência Orçamentáriada Agência: seria de boa prática que a agência reguladora tivesse um orçamento próprio para contratar recursos e desenvolver suas atividades. Esta independência reduzia a captura pelos interesses políticos-eleitorais.

x. Conhecimento Especializado (expertise) da Agência: a agência deve possuir um corpo técnico capacitado e recursos necessários para analisar questóes setoriais.

xi. Transparência, Comunicação e Prestação de Contas da Agência: as informaçóes devem ser disponibilizadas para todas as partes interessadas em tempo hábil, de maneira uniforme e acessível. A participação das partes interessadas em reunióes deve promover o intercâmbio de informações. Deve haver reporte das atividades do setor e da agência para as autoridades apropriadas e para sociedade.

xii. Poder de Mediação da Agência: é desejável a agência ter o poder de resolver disputas e conflitos entre as partes interessadas.

xiii. Poder de Normatização da Agência: a agência deve definir padróes técnicos, econômicos, contábeis, contratuais, jurídicos, tributários e ambientais.

xiv. Poder de Fiscalização e Auditoria da Agência: a agência deve realizar auditorias para verificar se as empresas estão em conformidade com as normas e procedimentos aplicáveis.

xv. Poder de Polícia da Agência: a agência pode aplicar sançôes, multas e suspensóes contratuais como instrumento de coibir as práticas inaceitáveis das empresas. 
Para avaliar as questôes listadas acima, foi elaborado um sistema de pontuação qualitativo para avaliar se o modelo regulatório do E\&P brasileiro está aderente às boas práticas regulatórias em dois períodos de tempo: após a ratificação da Lei do Petróleo em 1997 que criou ANP e os contratos de concessão; e após as reformas ocorridas entre 2009 e 2010 com a criação dos contratos de partilha da produção, criação da PPSA, mudança de atribuições da ANP e do CNPE. A fim de evitar um elevado grau de subjetivismo, o critério de pontuação seguiu os seguintes critérios: nota 1 - caso se verifique a aplicação do item; nota 0,5 - caso a aplicação seja questionável ou inconclusiva; e nota 0 (zero) - caso não se verifique a aplicação. Antes da aplicação do sistema de pontuação, serão levantadas as principais características do modelo regulatório do segmento de E\&P brasileiro.

\section{ASPECTOS GERAIS DO MODELO REGULATÓRIO BRASILEIRO}

Esta sessão foi baseada nos excelentes trabalhos de Caselli (2012) e Dias (2013). Caselli (2012) argumenta que a concepção estratégica do petróleo foi incorporada à consciência política nacional brasileira na década de $1930 \mathrm{com}$ a criação, através do Decreto-Lei n.o 395/1938, do primeiro órgão estatal voltado exclusivamente para este recurso natural, o Conselho Nacional do Petróleo (CNP). Em 1953 foi criada a Petróleo Brasileiro S.A (Petrobras), através da Lei n.o 2.004, ficando responsável pela exploração, produção e refino, em caráter monopolista, de todas as etapas da indústria do petróleo, exceto a distribuição e a revenda. Até a década de 1980, o modelo de regulação brasileiro estava baseado na ideia de Estado Monopolista Produtor. Na década de 1990, a partir da orientação mais liberal dos Governos de Fernando Collor e de Fernando Henrique, o CNP foi extinto, sendo substituído pelo Departamento Nacional de Combustíveis (DNC) e reformas institucionais modificaram o modelo regulatório brasileiro no segmento de E\&P posicionando o Estado para um papel Indutor e Regulador.

Período após a ratificação da Lei do Petróleo em 1997 que criou ANP e os contratos de concessão

Segundo Caselli (2012, p. 62-66), a aprovação da Emenda Constitucional (EC) $n^{\circ} 09$, promulgada em 09 de novembro de 1995, que dava nova redação ao parágrafo $1^{\circ}$ do artigo 177 da Constituição Federal, permitiu que as atividades da indústria do petróleo, de monopólio da União, até então desenvolvidas exclusivamente pela Petrobras, pudessem ser realizadas por empresas estatais e privadas. Em 15/01/1996, através do Decreto no 2.455 
de 14/01/1996, foi extinto o DNC. Com a promulgação da Lei n. 9.478 de 06/08/1997 (Lei do Petróleo), foi criada a Agência Nacional do Petróleo (ANP) e o Conselho Nacional de Política Energética (CNPE). O CNPE foi concebido para ser órgão de caráter consultivo, sinalizando a intenção do Governo em reduzir as interferências políticas nos processos de regulação econômica.

Quanto à Petrobras, manteve-se sob o controle acionário da União. Diante do novo desenho institucional aberto ao capital privado internacional, foi permitida à Petrobras a livre competição no Brasil e no exterior. De Souza Barçante et al (2013, p. 3) lembram que os blocos e campos solicitados pela Petrobras como de sua posse foram analisados pela ANP e no dia 6 de agosto de 1998 foi realizada a Rodada Zero, no qual foram concedidos à Petrobras 115 blocos, 51 áreas de desenvolvimento e 231 campos de produção, através da assinatura de 397 contratos de concessão que lhe conferiram o direito de exploração sob uma área superior a $450.000 \mathrm{Km}^{2}$, cumprindo a transição para um novo mercado concorrencial. Caso a estatal não obtivesse sucesso após três anos, os blocos deveriam ser devolvidos.

A participação do Ministério de Minas e Energia (MME), neste modelo, ficou restrita à presidência do CNPE, passando a ter uma função administrativa das questóes orçamentárias da ANP, sem qualquer atribuição atuação direta no setor.

"A Agência [ANP] passou a centralizar as deliberações e a elaboração de normas correspondentes à indústria do petróleo, gás natural e biocombustíveis no país, cabendo a ela, ainda, implementar as políticas energéticas definidas pelo governo. No que concerne às atribuiçóes da Agência, vale destacar que o princípio do Estado regulador estava ratificado nos termos da lei, especialmente no inciso primeiro do artigo $8^{\circ}$, o qual definiu a Agência como responsável pela implantação, em sua esfera de atribuiçốes, da política energética nacional, devendo enfatizar a '[...] garantia do suprimento de derivados de petróleo em todo o território nacional [...].' e a '[...] proteção dos interesses dos consumidores quanto a preço, qualidade e oferta dos produtos [...]' (BRASIL, 1997b). Por outro lado, o inciso nove do mesmo artigo conferiu à ANP a preocupação com o cumprimento das boas práticas de conservação e uso racional de energia e preservação do meio ambiente. Assim, pela primeira vez, a lei atribuía mais claramente ao regulador o papel de mediador de conflitos e zelador dos interesses da sociedade, do que de interventor na atividade econômica. O novo marco preocupou-se em manter com o Estado os poderes de anuir sobre as atividades integrantes da indústria do petróleo, devendo os agentes econômicos públicos e privados se submeterem aos regulamentos publicados pelo órgão regulador então criado". (CASELLI, 2012, p. 69) 
Caselli (2012, p. 70) chama a atenção de que, embora a redefinição de atribuições tenha introduzido elementos que garantissem menor intervenção direta do Estado na economia e proporcionassem um ambiente mais estável à atração de investimentos privados, o Estado, por meio da ANP, continuou com a atribuição de autorizar e fiscalizar o exercício das atividades da indústria, assim como de aplicar as sançóes administrativas cabíveis, de elaborar os editais de contrato de concessão e de executar o processo licitatório dos blocos exploratórios. Do ponto de vista da hierarquia administrativa, embora a ANP tenha sido criada mantendo o vínculo com o MME, ela foi instituída sob o regime jurídico de autarquia especial, com personalidade jurídica de direito público e autonomia patrimonial e administrativa, assegurando relativa independência decisória. A vinculação com o MME criou uma dependência nas questôes orçamentárias para a contratação de funcionários e realização de estudos e pesquisas. De forma geral, a nova concepção regulatória sinalizou ao mercado privado as intençôes do Governo em transmitir maior credibilidade e segurança institucional aos potencias investidores. Caselli (2012, p. 71) lembra que coube à ANP também a responsabilidade de controlar o recolhimento das participaçóes governamentais, incluindo o cálculo dos valores a serem pagos pelos concessionários a título de royalties e participações especiais (PE), bem como dos montantes a serem distribuídos aos respectivos beneficiários. O Decreto n. ${ }^{\circ} 2.455$ de 14/01/ 1998 consolidou a estrutura regimental da ANP, no que tange à implantação de recursos, e transferiu para ela todas as atividades, receitas, acervos técnicos, patrimônios e obrigaçôes do extinto DNC.

Segundo Caselli (2012, p. 72) e Dias (2013, p. 130-131), a Lei do Petróleo também ratificou que os depósitos de petróleo, gás natural e outros hidrocarbonetos existentes no território nacional, incluindo a parte em mar, continuavam pertencendo à União. Instituiu o exercício das atividades de exploração, desenvolvimento e produção de petróleo e de gás natural deveriam ser celebrados mediante contratos de concessão. A ANP também passou a ser o órgão responsável pela definição dos blocos que seriam licitados, retirando esta atribuição do MME, invertendo a política setorial antes controlada pelo Governo.

"Além de toda a regulação da indústria de petróleo e gás passar a ser executada por uma agência independente e dotada de atribuiçóes claramente definidas em lei, o próprio regime de exploração dos blocos por meio de contratos de concessão assegurava maior estabilidade e criava fortes incentivos ao investimento privado, ainda que os riscos da atividade fossem totalmente assumidos pelo concessionário. Isto porque, na hipótese de sucesso exploratório, o produto da lavra seria de sua propriedade, conforme explicitado no artigo 26 da Lei. (...) 
Art. 26. A concessão implica, para o concessionário, a obrigação de explorar, por sua conta e risco e, em caso de êxito, produzir petróleo ou gás natural em determinado bloco, conferindo-lhe a propriedade desses bens, após extraídos, com os encargos relativos ao pagamento dos tributos incidentes e das participaçóes legais ou contratuais correspondentes". (BRASIL, 1997b. Apud CASELLI, 2012, p. 72-73).

Neste quadro, a ANP detinha os requisitos para manter a certa estabilidade do modelo regulatório brasileiro, reduzir as arbitrariedades, as interferências políticas e as atitudes oportunistas do Governo, incentivar a atração de capital privado para o setor, e incentivar a ampliação dos investimentos em atividades exploratórias.

Deve-se notar que, cada modalidade de contratação está relacionada aos riscos envolvidos nas atividades de exploração em determinada região ou probabilidade de sucesso na produção de hidrocarbonetos. Desta forma, o Governo deve se preocupar com o estabelecimento de uma regulação que aumente a arrecadação e que, ao mesmo tempo, incentive as atividades empresariais no setor. Conforme Caselli (2012, p. 77), quanto maior o risco relacionado aos aspectos geológicos, menor tende a ser repartição da renda petrolífera das empresas com o Governo.

“(...) é importante explicitar que, considerando o objetivo dos governos de maximizar sua parcela de apropriação da renda econômica petrolífera, o que perpassa pelo estímulo às atividades de exploração e desenvolvimento, o autor salienta que os sistemas fiscais devem ser planejados de modo a: (i) assegurar um retorno justo para empresa e Estado; (ii) evitar especulação indevida; (iii) limitar a burocracia administrativa; (iv) oferecer flexibilidade; e (v) criar um ambiente competitivo e com maior eficiência dos mercados. No que concerne aos objetivos das empresas, por sua vez, o foco está em identificar campos de petróleo atrativos e rentáveis, que possibilitem a maximização das margens de lucros e minimização dos custos associados à exploração, desenvolvimento e produção. (JOHNSTON, 1994, p. 17-18. Apud CASELLI, 2012, p. 77).

Como visto acima, os contratos de concessão para exploração e produção de hidrocarbonetos no Brasil por empresas privadas veio com a promulgação da Lei do Petróleo em 1997, onde a oferta seria feita mediante processo de licitação de responsabilidade da ANP seguindo critérios técnicos, jurídicos e de preços. Neste tipo de contrato, a característica principal é o fato de da propriedade do recurso produzido ser transferido para a concessionária após sua extração do subsolo. Ou seja, o Estado concede a titularidade à empresa em troca do cumprimento de diversas obrigaçóes. Pelo lado fiscal, as empresas devem honrar o pagamento das participaçóes governamentais, quais sejam: bônus de assinatura, royalties, taxa de retenção de área e Participação Especial (PE) a depender do caso, conforme Gandra (2006). Quanto às 
contrapartidas não fiscais, pode-se destacar as seguintes exigências: cumprimento do Programa Exploratório Mínimo (PEM); e cumprimento do conteúdo local mínimo para a aquisição de bens e serviços no país. Deve-se notar que as empresas vencedoras nos processos licitatórios assumem todos os riscos: exploratórios, de desenvolvimento do campo, de produção, de descomissionamento, de danos ambientais e de licenciamento ambiental. A Figura 2 ilustra os principais atores do ambiente regulatório após a Lei do Petróleo.

Figura 2: Principais atores do ambiente regulatório após a Lei do Petróleo

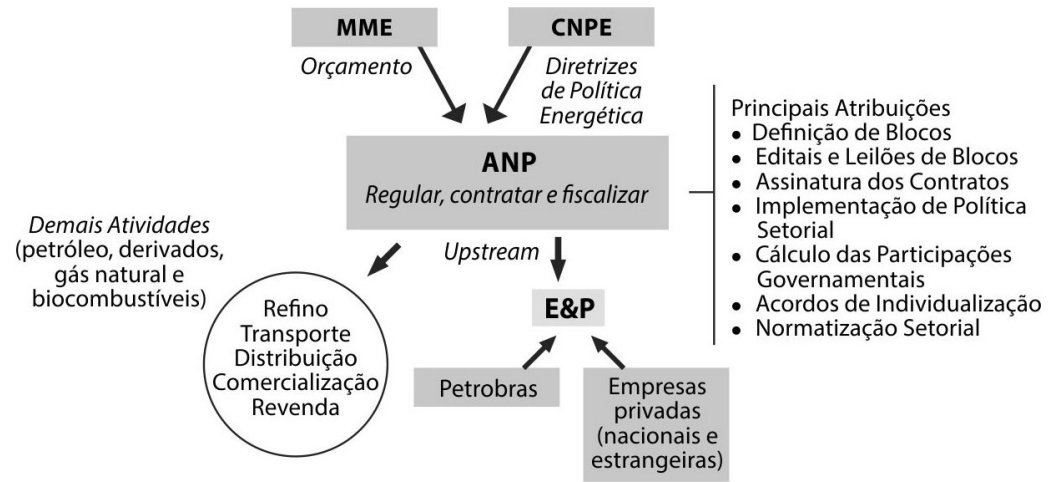

Fonte: Caselli (2012, p. 74)

Dias (2013, p. 196-198) conclui que o fim do monopólio da Petrobras e a introdução do regime de concessôes nas atividades upstream foi plenamente bem-sucedida quando adotado os seguintes critérios: crescimento das reservas e produção; atração de operadores internacionais e surgimento de empresas nacionais promovendo um ambiente mais competitivo; descoberta de novas fronteiras de exploração, em particular do pré-sal; desenvolvimento da cadeia produtiva de bens e serviços locais; crescimento substancial do setor petróleo no PIB; geração de empregos; crescimento da arrecadação das participaçóes governamentais; reestruturação da Petrobras aproximando-a das boas práticas gerenciais do setor; e consolidação dos instrumentos de governança regulatória, tal como a criação da $\mathrm{ANP}$ e das rodadas de licitação.

Período após as reformas ocorridas depois de 2010 com a criação dos contratos de partilha da produção, criação da PPSA, e mudanças de atribuições da ANP e do CNPE

Diante das descobertas de hidrocarbonetos na camada do pré-sal, entre 2006 e 2009, realizadas nas áreas sob o regime de concessão da Petrobras, 
com elevados índices de sucesso exploratório, especialmente em mar, Caselli (2012, p. 107-108) salienta que, levou o Governo a repensar o modelo contratual das atividades de E\&P no Brasil. "Geograficamente, tal camada é delimitada por uma área de cerca de 800 quilômetros de extensão e até 200 quilômetros de largura, em lâmina d'água entre 800 e 3.000 metros de profundidade e soterramento de 3 a 4 mil metros (BRASIL, 2009a. Apud CASELLI, 2012, p. 107)”. Do ponto de vista geológico, tais descobertas indicaram a ocorrência de reservatórios com elevado potencial petrolífero (com volume recuperável de recursos capaz de superar as reservas provadas nacionais em mais de 100\%) abaixo de uma extensa camada de sal, distribuída desde o Espírito Santo até o litoral norte de Santa Catarina. O fato das descobertas nas camadas do pré-sal apresentarem um elevado potencial petrolífero com óleo de elevado valor comercial, com grande quantidade de gás natural associado e a um baixo risco geológico mudou a percepção "prêmio-risco" das empresas e o posicionamento estratégico do Governo. Esta percepção, aliado a outros fatores, deu início a um processo de revisão do modelo regulatório vigente.

Segundo Caselli (2012, p. 115), em julho de 2008 foi instituída Comissão Interministerial, integrada pelo MME, a Casa Civil da Presidência da República (CCIVIL), o Ministério do Desenvolvimento, Indústria e Comércio Exterior (MDIC), Ministério da Fazenda (MF), o Ministério do Planejamento (MP), e os presidentes do Banco Nacional de Desenvolvimento Econômico e Social (BNDES) e da Petrobras e o Diretor-geral da ANP. Esta Comissão teve como objetivo propor as modificaçôes no modelo de E\&P vigente. $\mathrm{O}$ resultado foi enviado ao Congresso Nacional em setembro de 2009 na forma de quatro Projetos de Lei, sintetizados na Tabela 1.

"Percebe-se que, de acordo com a descrição dos projetos, o governo tinha como foco não apenas alterar a modalidade de contratação de empresas quando da exploração em áreas do pré-sal (PL n.o 5.938/2009), mas também criar uma empresa pública dedicada exclusivamente à gestão dos contratos destas áreas (PL n.o 5.939/2009), instituir um Fundo Social independente que pudesse garantir que o grande volume de recursos tributários obtidos com a exploração das áreas fossem também usufruídos pelas geraçôes futuras (PL n.․ 5.940/2009) e assegurar à Petrobras, por meio de uma cessão onerosa, as condiçóes financeiras necessárias à superação dos custos e da necessidade de investimento relativa ao desafio exploratório da nova fronteira de produção de petróleo e gás no país (PL n.o 5.941/2009)". (CASELLI, 2012, p. 115)

De Souza Barçante et al (2013, p. 7) ressaltam que a E.M.I. n.o 38/2009 deixou clara a intenção do Governo em "aumentar a participação da sociedade nos resultados da exploração de petróleo, de gás e de outros 
hidrocarbonetos fluidos nas áreas do pré-sal e estratégicas; destinar os recursos advindos de tal atividade a setores estruturalmente fundamentais para o desenvolvimento social e econômico; e fortalecer o complexo produtivo da indústria do petróleo e gás do País, preservando os interesses estratégicos nacionais".

Tabela 1 - Projetos de Lei apresentados pelo Executivo ao Congresso Nacional

\begin{tabular}{|l|l|}
\hline $\begin{array}{l}\text { Número de } \\
\text { projeto de lei }\end{array}$ & $\begin{array}{l}\text { Dispõe sobre a exploração e a produção de petróleo, de gás natural e de outros } \\
\text { hidrocarbonetos fluidos sob o regime de partilha de produção, em áreas do pr'-sal } \\
\text { e em áreas etratégicas, altera dispositivos da L ei n. 9.478, de 6 de agosto de 1997, } \\
\text { e dá outras providências. }\end{array}$ \\
\hline $5938 / 2009$ & $\begin{array}{l}\text { Autoriza o Poder Executivo a criar a empresa pública denominada Empresa } \\
\text { Brasileira de Administração de Petróleo e Gás Natural S.A. PETROSAL, e dá outras } \\
\text { providências. }\end{array}$ \\
\hline $5939 / 2009$ & Cria o Fundo Social (FS) e dá outras providências. \\
\hline $5940 / 2020$ & $\begin{array}{l}\text { Autora a União a ceder onerosamente à Petróleo Brasileiro S.A. (PETROBRAS) o } \\
\text { exercício das atividades de pesquisa e lavra de petróleo, de gás natural e de outros } \\
\text { hidrocarbonetos fluidos do que trata o inciso I do art. 177 da Constituição, e dá } \\
\text { outras providências. }\end{array}$ \\
\hline $5941 / 2020$ &
\end{tabular}

Fonte: Caselli (2012, p. 115).

A inclusão da contratação de partilha veio para atender às expectativas do Governo em relação aos interesses estratégicos de arrecadação, controle do ritmo de exploração dos recursos e controle da produção. Baseado nesta nova percepção de "prêmio-risco", o novo modelo licitatório nas áreas do pré-sal passou a premiar como vencedor aquele que oferecesse (título de excedente em óleo) a maior parcela ao Estado.

"Desta forma, é possível identificar que revisão marco legal, em particular para as atividades a serem exercidas na província do pré-sal e nas áreas consideradas estratégicas, estava ancorado em cinco fatores principais: nas características geológicas diferenciadas da província petrolífera então descoberta; no cenário internacional positivo do ponto de vista do preço do petróleo; na importância estratégica permanente do óleo como fonte energética dominante mundialmente; no fortalecimento da Petrobras como empresa líder no segmento de E\&P no Brasil, mesmo após o processo de abertura econômica; e no interesse explícito do governo, como ente político, de aumentar o controle do Estado sobre os recursos petrolíferos nacionais, que havia se reduzido desde a flexibilização do monopólio estatal e da instituição do contrato de concessão como modalidade única de contratação de empresas para as atividades ligadas ao segmento de upstream". (CASELLI, 2012, p. 118) 
Segundo Caselli (2012, p. 120-121), o Projeto de Lei n.o 5.938/2009 foi aprovado pelo Legislativo e convertido na Lei n.o 12.276 de 30/07/2010, em que a União autorizou, mediamente assinatura de contrato específico, ceder onerosamente à Petrobras áreas (ainda não concedidas localizadas no pré-sal e em regime de dispensa de licitação) para o exercício das atividades de pesquisa e lavra de hidrocarbonetos. A efetivação deste contrato de cessão de direitos ficou limitado à produção de cinco bilhões de barris de óleo equivalente (boe). Este contrato foi previamente aprovado pelo CNPE, cabendo à ANP a responsabilidade de obter laudos técnicos para avaliar os volumes e valores a serem potencialmente produzidos pela Petrobras nas respectivas áreas do pré-sal, bem como de regular e fiscalizar as atividades realizadas no âmbito do contrato de cessão onerosa. Este novo modelo tornou a Petrobras detentora do monopólio na exploração, desenvolvimento e produção das áreas de interesse do Governo (através do MME e do CNPE) sem processos licitatórios. Isto é, de certa forma nestas áreas estratégicas, houve uma volta ao modelo de Estado Monopolista Produtor cabendo a ele receber a parcela do excedente da produção, descontados os custos incorridos nas atividades.

Além disso, Caselli (2012, p. 121-122) acrescenta que, o Projeto de Lei n.o 5.939/2009 foi aprovado pelo Legislativo e convertido na Lei n.o 12.304 de 2 de agosto de 2010, em que o Poder Executivo autorizou criar a Empresa Brasileira de Administração de Petróleo e Gás Natural S.A (Pré-Sal Petróleo S.A. - PPSA), vinculada ao MME, com a atribuição de representar a União na gestão dos contratos de partilha da produção no que diz respeito: ao cumprimento das exigências de conteúdo local; às avaliaçóes dos critérios técnicos e econômicos dos planos relacionados às atividades exploratórias desenvolvidas pelas empresas contratadas sob o regime de partilha; às auditorias e acompanhamento os custos operacionais e dos investimentos em exploração, desenvolvimento e produção dos campos de petróleo; à gestão da comercialização dos hidrocarbonetos representando a União; e quando as jazidas de petróleo estejam estendidas às áreas não concedidas ou não contratadas sob o regime de partilha de produção, a PPSA fica responsável por representar a União nos procedimentos de unitização da produção, cuja competência era anteriormente exercida exclusivamente pela ANP.

É importante ressaltar que o processo decisório da PPSA é constituído por um Conselho de Administração e uma Diretoria Executiva, ambos com cinco integrantes. Em todos os casos, os nomes serão indicados pelo Presidente da República, sem a necessidade de aprovação pelo Senado Federal. A empresa estará sujeita à supervisão do MME e à fiscalização da Controladoria-Geral da União (CGU) e do Tribunal de Contas da União (TCU). 
Ressalta-se ainda que, no caso deste novo agente, a independência institucional difere da aplicável à ANP, onde os diretores são indicados pelo Presidente da República, cujas escolhas são submetidas à aprovação do Senado Federal, garantindo a estabilidade de mandatos e uma certa independência no processo de deliberação.

Já os riscos das atividades de exploração e produção no regime de partilha continuam com as concessionárias vencedoras do processo licitatório. Nos blocos sob o regime de partilha, a Petrobras passaria a atuar como operadora única, sendo-lhe garantida a participação mínima de $30 \%$ nos casos em que a licitação venha a ser vencida por outro consórcio de empresas. O primeiro leilão no regime de partilha foi o da área de Libra, em 2013, arrematada pelo consórcio formado por Petrobras, Shell, Total, CNOOC e CNPC, sem disputa. Neste modelo os parceiros vencedores do consórcio assumem também o "risco Petrobras". Isto é, sendo a Petrobras a operadora compulsória, há o risco das decisóes da joint venture serem contaminadas por influencias e demandas do Governo, dos partidos políticos e de grupos sociais diversos tornando a implementação dos projetos mais lenta e onerosa.

"Pelo regime de partilha, o contratado exercerá, por sua conta e risco, as atividades de exploração e produção dos hidrocarbonetos, tendo direito, na hipótese de descoberta comercial, à apropriação do custo em óleo, do volume da produção correspondente aos royalties devidos, bem como de parcela do excedente em óleo, na proporção, condiçốes e prazos estabelecidos em contrato. Destaca-se que o novo regime de contratação aplica-se às áreas do pré-sal e demais consideradas estratégicas, conforme delimitação legal”. (CASELLI, 2012, p. 123)

Caselli (2012, p. 124) e De Souza Barçante et al (2013, p. 7) lembram que, quanto ao processo licitatório, a introdução da Lei n.o 12.351/2010 criou o regime de partilha da produção, onde o critério da oferta de maior excedente em óleo à União, partindo de um percentual mínimo estabelecido pelo CNPE, seria válido para estabelecer o vencedor. Ou seja, houve grande alteração nos incentivos oferecidos para as empresas interessadas no setor, deixando clara a pretensão do Governo em aumentar as receitas de apropriação das rendas petrolíferas. As questóes relativas a PEM, conteúdo local mínimo e bônus de assinatura passam a ter um valor fixo previamente definido no edital de licitação. A Lei n.o 12.351/2010 cria também o Fundo Social (FS) para destinação dos recursos.

Mas diante da crise econômica em 2015 e 2016, do elevado endividamento e falta de caixa da Petrobras para realizar novos investimento, em 05/10/2016, a Câmara dos Deputados aprovou o projeto de lei que retirou a obrigatoriedade da participação da empresa na exploração do petróleo do pré-sal. Além disso, com a intenção de atrair mais investimentos para o setor, 
em 19/07/2017, a ANP publicou o edital e o modelo de contrato da $14^{\underline{a}}$ Rodada de Licitaçóes de Blocos para Exploração e Produção de Petróleo e Gás Natural, sob regime de concessão, retirando a exigência de conteúdo local. Esta medida mudou os incentivos no segmento de E\&P e mostrou uma certa descontinuidade com os objetivos das políticas industriais de desenvolvimento de uma cadeia de fornecedores no Brasil.

Através da Figura 3, Caselli (2012, p. 128) ilustra os papeis dos atores presentes no ambiente regulatório do setor de E\&P brasileiro a depender da forma de contratação, onde pode-se perceber alterações significativas na estrutura regulatória. Além da criação da PPSA, novas competências foram definidas para o MME, CNPE e ANP, fortalecendo o poder de influência do Governo. Caselli (2012, p. 124-126) destaca que, no regime de partilha da produção, os novos contratos passam a ser celebrados pela União, por intermédio do MME, e não mais pela ANP. Ao mesmo tempo, o novo modelo reforçou o papel de protagonista da Petrobras nas atividades de exploração e produção de petróleo no país, uma vez que a União ficou autorizada a contratar em áreas estratégicas, diretamente a Petrobras, dispensando licitaçóes. Através da Lei n.o 12.351/2010, o CNPE passou a ter uma atribuição mais efetiva na regulação setorial, propondo ao Presidente da República políticas nacionais e medidas destinadas à promoção do aproveitamento racional

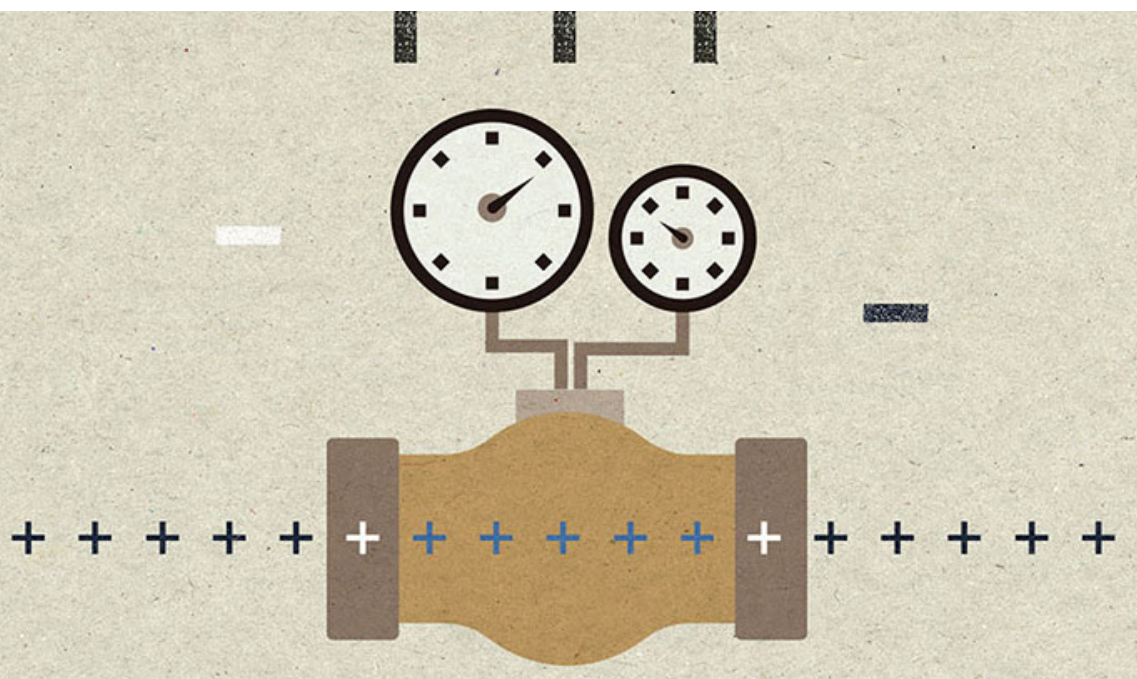


dos recursos energéticos; validando os parâmetros técnicos e econômicos a serem aplicados aos contratos de partilha de produção; e autorizando a ANP a licitação de blocos nos contratos de partilha de produção e também de concessão. Além disso, o MME passou a ter acesso irrestrito e gratuito ao acervo técnico de dados e informações das bacias sedimentares brasileiras da ANP.

No novo modelo de contratação, embora a gestão dos contratos tenha sido delegada à PPSA como representante da União, a fiscalização e a regulação das atividades realizadas sob o regime de partilha de produção ficaram a cargo da ANP, bem como a promoção das licitações. A ANP manteve a atribuição de analisar e aprovar os planos de exploração e de desenvolvimento relativos às atividades a serem executadas pela empresa contratada no âmbito da partilha de produção. Neste aspecto, Caselli (2012, p. 126) observou intercessão de competências entre ANP e PPSA.

Figura 3 - O ambiente regulatório de E\&P de P\&G após legislação do pré-sal

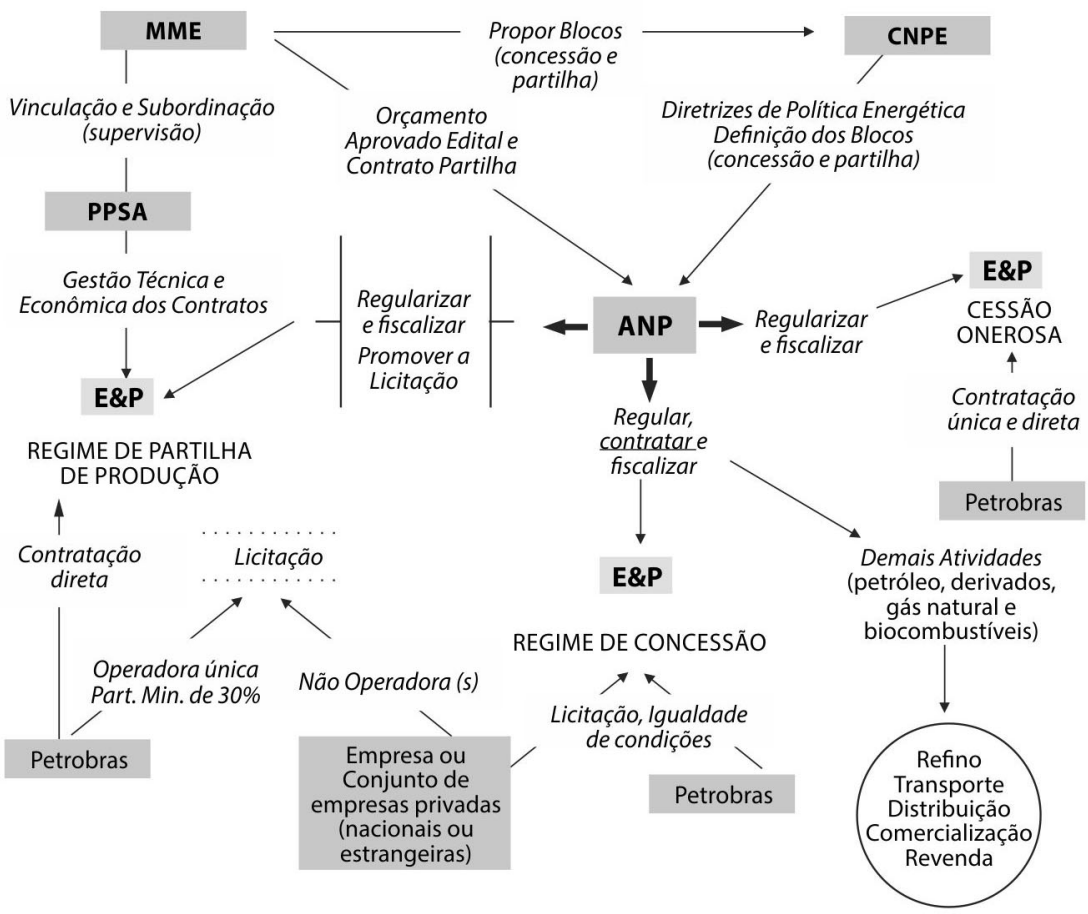

Fonte: Caselli (2012, p. 128). Atualizando a figura acima, atualmente a Petrobras não mais tem a obrigatoriedade de ser operadora única e deter 30\% de participação nos consórcios vencedores. 


\section{CONSIDERAÇÕES FINAIS}

A Tabela 2 resume a análise qualitativa de pontuação do modelo regulatório brasileiro de E\&P em relação a aderência às boas práticas em dois períodos de tempo: após a ratificaçâo da Lei do Petróleo em 1997; e após as reformas ocorridas em 2010. Os critérios de pontuação adotados foram inspirados na literatura econômica corrente sobre regulação e não pretendeu ser exaustivo. Considerando uma faixa de pontuação de 0 a 15, o modelo regulatório brasileiro de $\mathrm{E} \& \mathrm{P}$, nos dois períodos, se mostrou aderente às boas práticas, preenchendo quase todos os requisitos. Até 2010, a pontuação foi 13,00 e após 2010, a pontuação foi 11,50. A queda na pontuação após 2010 se deve: claramente à maior complexidade do sistema; às dúvidas quanto à previsibilidade do sistema; e ao questionável ganho de eficácia oferecido pelas mudanças. 


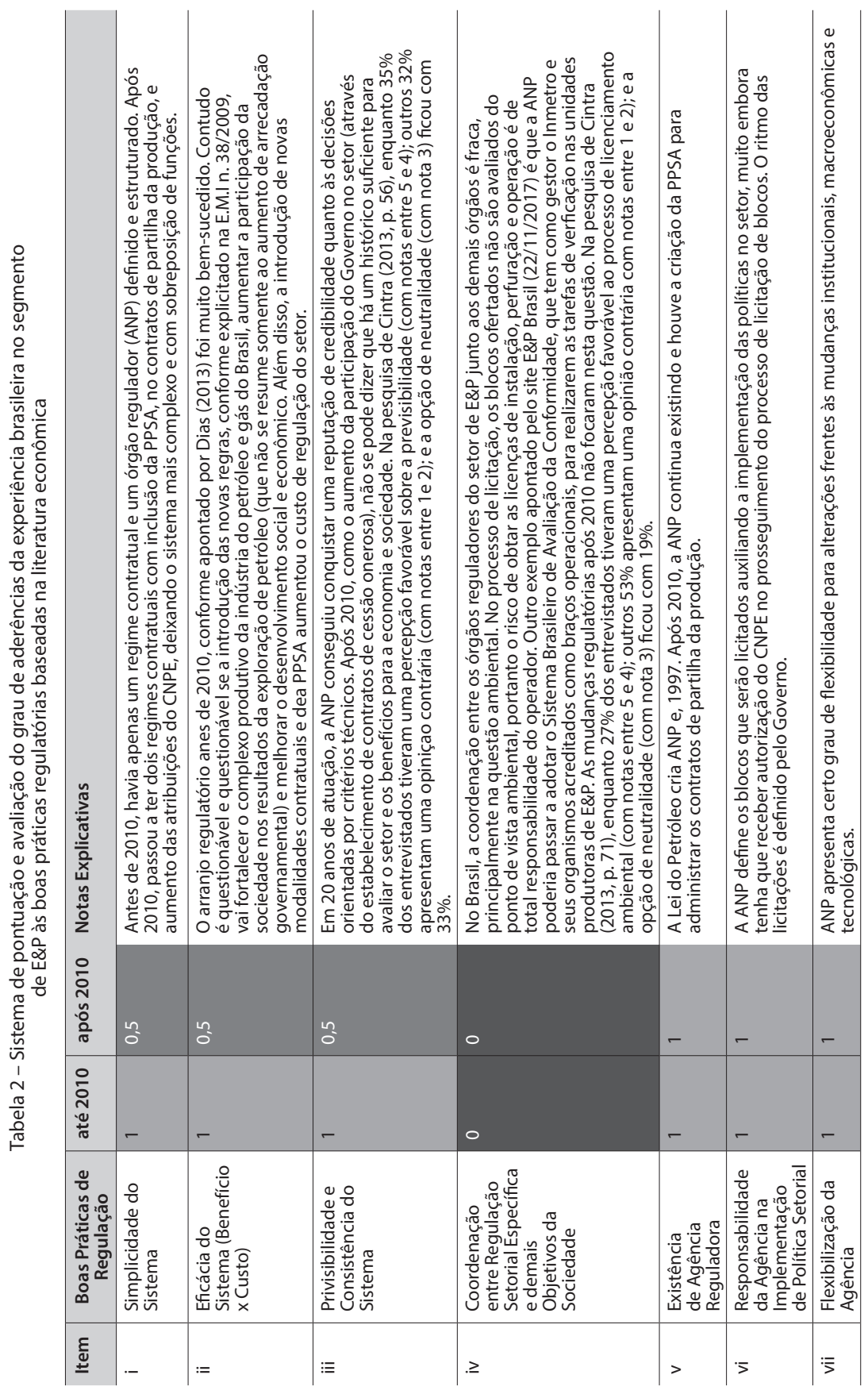




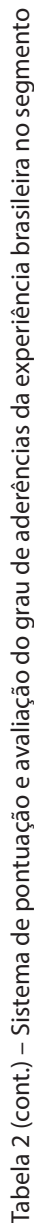

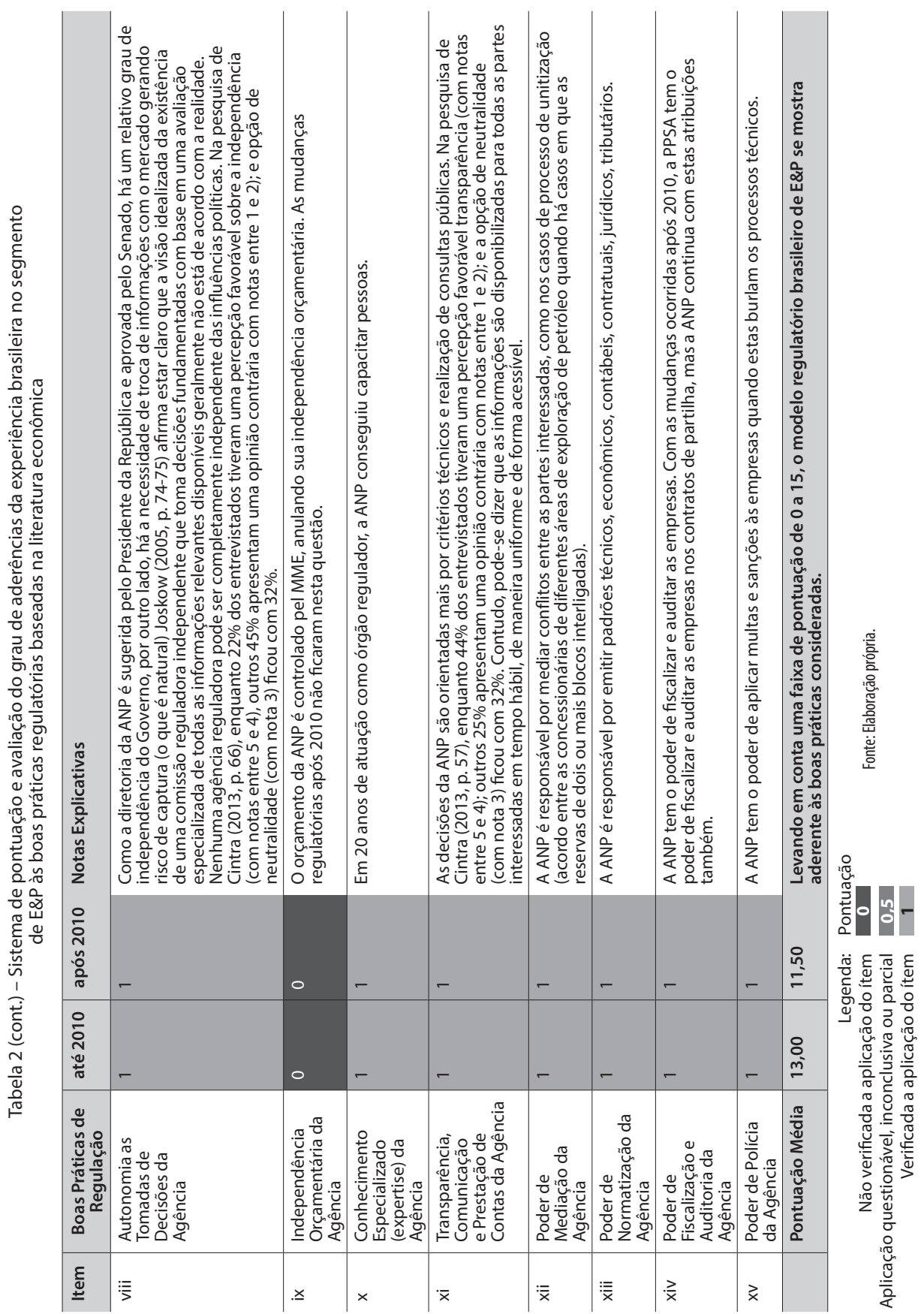


Deve-se notar que um ambiente regulatório onde coexiste duas modalidades de contratação e sobreposição de atribuições aumenta a complexidade, eleva a avaliação de riscos das empresas interessadas e aumenta o risco de falhas de coordenação dos órgãos governamentais. Conforme foi visto, no regime de partilha de produção, o óleo e o gás produzidos pertencem ao Estado, sendo assim as concessionárias devem: pagar valores fixos de bônus de assinatura; pagar valores variáveis (de acordo com a produção e preço do óleo) relativos ao excedente em óleo; pagar Royalties; e arcar com PEM e conteúdo local pré-definidos. Neste arranjo, a assinatura dos contratos se dá entre as concessionárias e a PPSA, aumentando de certa forma a participação do Governo nas atividades de E\&P sem incorrer maiores riscos inerentes à atividade.

É questionável se a introdução das novas regras, conforme explicitado na E.M.I. n.o 38/2009, vai fortalecer o complexo produtivo da indústria do petróleo e gás do Brasil, aumentar a participação da sociedade nos resultados da exploração de petróleo (que não se resume somente no aumento de arrecadação governamental) e melhorar o desenvolvimento social e econômico. De Souza Barçante et al (2013, p. 12) destacam que o sucesso do novo modelo regulatório depende da continuidade dos investimentos da Petrobras e das demais empresas do setor; da coordenação da regulação do setor de E\&P com as políticas macroeconômicas, com as políticas industriais, com as políticas ambientais, tecnológicas etc; e na repartição e aplicação focada dos recursos petrolíferos.

A previsibilidade e consistência do sistema dependem da estabilidade das regras do negócio estão diretamente ligadas "risco regulatório". Para Cintra (2013, p. 56), que realizou uma pesquisa de campo para levantar a percepção de profissionais do setor de petróleo e gás natural sobre a atratividade do upstream brasileiro, a influência do tempo vem gradualmente cimentando a estabilidade do regime de concessão e assegurando certa previsibilidade; de outra parte, o Brasil implementou importantes mudanças em seu modelo regulatório para o setor $\mathrm{E} \& \mathrm{P}$, como por exemplo, o regime de contrato de partilha de produção no pré-sal e os contratos de cessão onerosa nas áreas estratégicas, que comprometeu esta estabilidade. Ou seja, um sistema que vinha ganhando confiança, sofreu uma drástica mudança, o que torna a questão ainda inconclusiva do ponto de vista avaliativo.

\section{Nota}

'Uma versão deste artigo foi apresentada como trabalho técnico (IBP1241_18) na Rio Oil \& Gas Expo and Conference 2018, realizada no período de 24 a 27 de setembro de 2018, na cidade do Rio de Janeiro. 


\section{Referências}

BALDWIN, R.; CAVE, M. \& LODGE, Mz. The Oxford Handbook of Regulation: Theory, Strategy, and Practice. Oxford University Press, 2012.

BERG, S. V. Infrastructure Regulation: Risk, Return, and Performance. University of Florida: Public Utility Research Center, July 4, 2001.

BRASIL. E.M.I. n. ${ }^{\circ} 00038$ - MME/MF/ MDIC/MP/CCIVIL de 31/08/2009. Disponível em: < https://bit.ly/35cQIry > Acesso em: 21 nov. 2017.

CASELLI, B. C. Redesenho institucional e arranjos contratuais: uma análise da regulação e da indústria de petróleo e gás natural no upstream brasileiro. Rio de Janeiro: UFRJ/PPED, 2012 (Dissertação de Mestrado).

CINTRA, M. A. L. C. Atratividade do upstream brasileiro: uma percepção de profissionais do setor de petróleo e gás natural. Rio de Janeiro: UFRJ/PPED, 2013 (Dissertação de Mestrado).

DE SOUZA BARÇANTE, M. F.; et al. "Os marcos regulatórios da indústria de petróleo brasileira: análise SWOT. In: Anais doIX Congresso Nacional de Excelência em Gestão. Rio de Janeiro: Junho de 2013.

DIAS, G. G. Mudança Institucional e Desenvolvimento: O Caso da Indústria do Petróleo no Brasil. Rio de Janeiro: UFRJ/ PPED, 2013 (Tese de Doutorado).

E\&P BRASIL. Conformidades multiplicadas. Publicada 22 nov. 2017. Disponível em: https://bit.ly/35gfaIL. Acesso em: 22 nov. 2019.

FERRAZ, Clarice. "A importância das instituições para a transição energética brasileira". Boletim Infopetro - Petróleo \& Gás Brasil, ano 17, n. 1. Grupo de Economia da Energia (IE/UFRJ): Março-Abril de 2017, p. 7-13.
GANDRA, R. M. "Justificativas regulatórias para o segmento de Exploração e Produção (E\&P) no Brasil entre 1997 e 2017". Desenvolvimento em Debate, v. 6, n. 1. Rio de Janeiro: Instituto Nacional de Ciência e Tecnologia em Políticas Públicas, Estratégias e Desenvolvimento (INCT/ PPED), 2018, pp.27-41.

GANDRA, R. M. "O Impacto da Participação Especial em Campos Gigantes Offshore de Petróleo". Revista Produção, n. 2, v. 16. São Paulo: ABEPRO/POLI-USP, Maio-Agosto de 2006, pp. 274-286.

GANDRA, R. M. "Projetos de Elevado Risco em Petróleo". Blog do Petróleo \& da Energia em 31 out. 2014 (entrevista). Disponivel em: https://bit.ly/3aKTolo. Acesso em: 21 nov. 2017.

JOSKOW, P. L. Regulation of Natural Monopolies. Cambridge Press, MIT, 2005. NEWBERY, D. M. Privatisation, Restructuring and Regulation of Network Utilities. The Walras-Pareto Lecturesat the École des Hautes Études Commerciales Université de Lausanne. London: The MIT Press, 1999.

NORTH, D. C. Institutions, Institutional Change and Economic Performance. New York: Cambridge University Press, 1990. RAUD-MATTEDI, C. "A construção social do mercado em Durkheim e Weber: análise do papel das instituições na sociologia econômica clássica". Revista Brasileira de Ciências Sociais (RBCS), v. 20, n. 57, 2005. TOLMASQUIN, M. T. \& PINTO JR., H. Q. (org.). Marcos regulatórios da indústria mundial do petróleo. Rio de Janeiro: Editora Synergia: EPE, 2011. 